\title{
Moderating Influence of Strategic Human Resources Management Practices on Small-Medium Firm Performance
}

\section{Kowo Solomon Akpoviroro}

$\mathrm{PhD}$, Assistant Professor, Department of Business and Entrepreneurship, Kwara State University, Malete, Nigeria

\section{Akinrinola Olalekan}

PhD, Assistant Professor, Department of Accounting, Babcock University, Ogun State, Nigeria

\section{Salau Abdulazeez Alhaji}

$\mathrm{PhD}$, Assistant Professor, Department of Business and Entrepreneurship, Kwara State University, Malete, Nigeria

\begin{abstract}
The paper examines the link between Strategic Human Resources Management (SHRM) and Small-Medium Firm (SMF) Performance. The objectives of the study are to explore the link between Strategic SHRM practices and Small-Medium Firm Performance and also to examine whether factors like size, maturity, planning level, and availability of human resource department make any difference in practicing SHRM to the selected firms in the food industry in Nigeria. Survey research design, which gives room for the use of a questionnaire, was employed. Regression, ANOVA, and multiple regression analysis were used to test the hypothesis. The findings show that $\mathrm{R}^{2}$ value of 0.511 reveals that Strategic Human Resources Management independently accounts for $51.1 \%$ of the variation of Small-Medium Firm Performance, which reveal that there is a significant relationship between Strategic Human Resources Management and Small-Medium Firm Performance. $\mathrm{R}^{2}$ value of 0.658 reveals that Size, maturity, planning level and availability of HR department (HRD) accounts for $65.8 \%$ of the variation in SHRM practices, which reveal that Size, maturity, planning level and availability of HR department significantly affect SHRM practices of the firms. Thus, the study recommends SMF to find ways to manage human resources more efficiently and effectively in order to remain competitive in the globalized market.
\end{abstract}

Keywords: Small-Medium Firm, Human Resources, Strategic Human Resources Management Performance.

JEL Classification: L11, L25, O15.

Cite as: Akpoviroro, K. S., Olalekan, A., Alhaji, S. A. (2018). Moderating Influence of Strategic Human Resources Management Practices on Small-Medium Firm Performance. Business Ethics and Leadership, 2(4), 99-107. http://doi.org/10.21272/bel.2(4).99-107.2018.

(C) The Authors, 2018. This article is published with open access at Sumy State University.

\section{Introduction}

Blackwell, Mark, \& Akhtar (2013) posit that the need for Organization to pay attention to the best practice of Strategic Human Resources Practices is now necessary. Human resources were first used in the early 1900s and then more widely in the 1960s for the people who work for the organization, in aggregate (Butler, \& Lee, 2013). HRM is really employee management with an emphasis on those employees as assets of the business. In this context, employees are regarded as human capital. As with other business assets, the goal is to make effective use of employees, eradicating risk and maximizing the rate of return on investment. Ding, \& Akhtar (2015) opined that the modern HR Technology term, human capital management has come into more frequent use than the term, HRM, with the widespread adoption by large and midsize companies and other organizations of software to manage many HR functions (Sekkel, \& Araújo, 2010). Human resource is a department within a company whose responsibilities include searching for employees and training them, helping with conflict resolution, and organizing and helping with benefits. In other words, the HR department works with employees, their issues and their needs.

Flyn, Doodley, \& Cormican (2013) noted that Human resource strategy is completing all of these responsibilities, only this time those responsibilities are completed with the overall goals. Heneman, Tansky, \& Camp (2010) postulate that Human Resource Management includes conducting job analyses, planning personnel needs, recruiting the right people for the job, orienting and training, managing wages and salaries, providing benefits and incentives, evaluating performance, resolving disputes, and communicating with all 
employees at all levels. Examples of core qualities of HR management are extensive knowledge of the industry, leadership, and effective negotiation skills. Formerly called personnel management. Blackwell, Mark, \& Akhtar (2013) highlight the upward and downward influence of strategy formation. The upward influence means the consideration of organizational circumstances and strategic alternatives; on the contrary, the downward influence refers to match of strategic context with organizational arrangements to implement strategic objectives (Love, Priem, \& Lumpkin, 2002). Over the last decade, the pattern of HRM practices in Nigeria has been gradually changing which is reflected in a study conducted by Filippetti (2015) through analyzing the annual reports of 40 randomly selected companies and show different HRM related exposures. Johne (2013) emphasized the linkage between HRM and Corporate Strategy. He found Michel porter's generic Cost leadership; Differentiation and Focus strategies have a significant impact on the HRM practices of the firms. A comparative scenario depicted by Ding, \& Akhtar (2015) concluded with better HRM practices in the private sector relative to the public sector. The previous related literature survey on HRM clearly mentions the lacking of adequate focus on comprehensive HRM practices, and particularly, the strategic focus in different functions of HRM.

\section{Statement of Research Problems}

Although previous researches were based on the different functions of human resource management in Nigeria context, a comprehensive study on the human resource practices from strategic outlook was yet to be conducted (Chew, 2016). Human capital as a core competence of successful strategy implementation can only be configured through efficient acquisition, development and retention of employees. The departures of this study from previous human resource management literature are in two ways. Firstly, this research essentially focuses on the prevalence of SHRM practices in business organizations. Secondly, this study has a unique focus to draw a relationship between human capital developments with organizational strategies of the firms; this research also strives to reveal the viable factors that are acting as differentiators to practice SHRM in Nigeria. This research is exploratory in nature, which wishes to explore the link between Strategic Human Resources Management practices and Small-Medium Firm Performance (SMFP) also examines whether factors like size, maturity, planning level, and availability of human resource department make any difference in practicing SHRM to the selected firms. Hence, the whole research is based on the following hypothesis.

\section{Hypotheses One}

Ho: There is no significant relationship between Strategic Human Resources Management practices and SmallMedium Firm Performance

Hi: There is a significant relationship between Strategic Human Resources Management practices and SmallMedium Firm Performance

\section{Hypotheses Two}

Ho: Size, maturity, planning level and availability of HR department do not significantly affect the SHRM practices of the organizations.

Hi: Size, maturity, planning level and availability of HR department significantly affect SHRM practices of the organizations.

\section{Literature Review}

\section{The Concept of Strategic Human Resources Management Practices}

In a competitive business situation, an organization has to continuously struggle for competitive advantage, otherwise, its survival in long run may be endangered (Flynn, Doodley, \& Cormican, 2013). To gain competitive advantage, organizations have to formulate strategy, which is technically and cost wise difficult to imitate for the competitors (Goel, 2013). In Nigeria, the corporate sector is steadily growing with the passage of economic development. Firms in this sector are originated both from the national and international arena with a versatile range of intervention in both manufacturing and service industries. No doubt, human capital is a pivotal determinant to continue such evolution and sustainability of the firms. Previous researches pertinently focused on the functions of human resource practices while little attention was given to the alignment of firms' HR practices with their strategic standpoint. This study intends to focus on whether SHRM is practiced in the context of Nigeria and the factors that influence such practices (Ding, \& Akhta, 2015). Furthermore, Craig \& Hart (2005) pointed out that among the many organizational elements, size, maturity, and planning level have been particularly focused in academic literature. Frequently, a number of full-time employees is used as an 
indicator of organization size (Becker, 1964). Researchers have focused on the relationship between organization size and strategic planning, while some of the studies highlighted the benefits of organization size. Kyrgidou (2009) stresses the significance of size for larger organizations for the purpose of control and coordination while Carlson, Upton, \& Seaman (2006) found the intense effect of size on organization structure. According to Robert (2003) after exceeding 1500 employees, formalization of work become less important, which partially supports the previous research finding that a positive relationship exists between the formality of planning and organization size. Bharadwai, \& Menon (2010) emphasized the capacity of big firms to have more resources. Lin et al. (2008) conclude as a clear mandate of the large firms to engage in planning activity than those of smaller firms. Otero, Lindman, \& Fernández (2009) found increase planning of large firms in a dynamic environment, which supports the argument of Johne (2013) that superior resource allows large firms to have greater 'strategic flexibility'. However, in terms of financial resources and managerial time, small firms are less likely to respond (Berker, 1964). Moreover, large firms achieve enhanced specialization due to economies of scale and experimental learning (Hurley, \& Hult, 1998). On the contrary, size is revealed in a conflicting relationship with strategic flexibility, which Weerdt, Verwaal, and Volberda (2007) investigated and found that large firms have a better capacity to recognize environmental changes while simultaneously decreases responding ability to it. In terms of planning horizon, firm's size, type and age are found as influencing factors (Harrison, 1995; Larsen, Tonge, \& Ito, 1998), while plan is found to be independent of size $\&$ type of the company and no significant differences exist in the planning horizon of small and large firms (Kellermanns, Eddleston, Sarathy, \& Murphy, 2010). The relationship between strategic planning and organizational age has been focused on various dimensions. Loderer and Waelchli (2009) discussed the changing ability and growth as a result of age while Othman, \& Tec (2013) reviewed the intensity of planning and its benefits by comparing old and young firms. Rae, \& Carswell (2000) pointed the effect of organization age on performance in the context of organizational inertia, which also supports the view of Rogers (2010) that obsolete skills, knowledge and abilities bring organizational decay and hence lead the older firms to be less flexible in responding to profitable innovations created in the external market. Pfeffer (1994) studied the positive relationship between the firm's growth and age. Moreover, young firms, in a large extent are calibrated in activity analysis and advanced planning. The effect of age has been studied in the context of the planning horizon, which referred as the future time period that decision makers consider during planning. Such a horizon is determined by the factors like firm's age, type and size (Jiménez, \& Sanz-Valle, 2005). The young firms were found with higher planning intensity than those of matured firms, which Risseeuw and Masurel (1994) reveal as because of projecting expectations with plans to raise the debt and equity capital. However, Kyrgidou (2009) predicts such a relationship between the firm's maturity and planning since a large firm is likely to plan more than young ones (Barney, 1991). For the planning level, mostly the literature was found related to the corporate level. Rogers (2010) argues that strategy to be broken in sub-strategies while Butler, \& Lee (2013) focused on the set of hierarchies to operationalize, which supports the research finding that team effort and contributions of various levels are required for strategy synchronization.

\section{Five Steps to an Effective Small-Medium Firm Performance Evaluation System.}

Ding, \& Akhtar (2015) say that a traditional performance evaluation system has only been about single process. The managers and employees would have a review meeting once in a year where the employee's performance would be given a numerical rating based on their results and at times, a ranking would also be given after comparing their work with other employees. This system has now started acting as a huge demotivation for the employees as it is not structured correctly. Let us look at a few ways that the performance evaluation system can be altered to make it more efficient and effective.

\section{(a) Review of the Current System:}

To begin with, firms need to present a case to senior management explaining to them as to how there is room for improvement in the current performance system. In order to do that, an Organization needa to provide a baseline metric to which you can compare your system to track the difference in the performance development. The current system can be reviewed through the below parameters (Chew, 2016).

$>$ How often is the evaluation process conducted?

$>$ Do the employees receive a regular feedback?

D Does the process help capitalize on the employee's potential and also help develop new skills?

$>$ Are the appraisal and the benefits given in an unbiased manner?

Once the Firms have answers to these question, create the new system. A change in the evaluation system will result in an immediate shift in the performance. 


\section{(b) Approval from the Management:}

Communicate with senior management on how the current performance system needs improvement. $70 \%$ of companies today are shifting towards a modern approach that focuses on developing a closed loop feedback system wherein the feedback cycle is continuous in nature and helps in managing the talent in a better manner (Rogers, 2010). While presenting the review of the performance system, explain how planned and frequent feedback and coaching will help improve the employee's performance, adding on to the company's overall performance. Additionally, also explain that the new system can be developed keeping in mind the areas that need to be improved in the evaluation process, helping the firms on multiple fronts (Sekkel, \& Araújo, 2010).

\section{(c) Set Guidelines:}

Rogers (2010) says before implementing the new system, there is a need to run it through the employees to make them a part of the process as their feedback is equally important in making the process successful. The HR Manager needs to ensure that the assessors who will be conducting the process should understand the know-how of the process - how to conduct evaluations, to give the right feedback, to accept the feedback from the assessed, etc.

\section{(d) Implement the New System:}

Once a buy-in has been received from the senior management, implement the new performance system. This should be beyond abolishing the annual reviews; it should be about replacing old techniques with the newer ones which would benefit the employees as well as the organization. While implementing the system, ensure incorporating the below points (Bharadwai, \& Menon, 2010).

$>$ KRA (Key Result Areas) - Define the KRA's of all the firm employees individually and let the evaluation be based strictly on them.

$>\mathrm{R}$ and R (Reward and Recognition) - Recognized and Reward employees every quarter, this will act as a morale booster as well as a guideline for the annual evaluation.

> Guide poor performers - Recognize and guide underperformers, understand their strengths and weaknesses and helping employees accordingly. This will help balance the overall performance of the firms. Link the performance appraisal results with relevant training programmes, identify the gaps by analyzing the performance and provide appropriate inputs for the training. It is important to assess the results of the training programme at regular intervals to make it a success.

\section{(e) Evaluate the New System:}

Based on the baseline metric originally established, HR Managers should do a comparative analysis after 6 months. Track the changes in the employees, their productivity and the overall performance of the organization. If they note a substantial difference, then they should report the same to the senior management to make them aware of the success of the new evaluation system. And in case he doesn't, then he needs to analyze the new system, check if there is missed out on any critical areas and if the new system needs to be reworked. HR Managers should ensure that the new system incorporates the employee's and employer's perspective equally and is as less subjective as possible. Employees are the organization's best assets and they should be a priority. Through performance evaluation system the organizations have an opportunity to transform their employee's work experience into a motivating and content one allowing them to bring their best to work every day .

\section{Effective Role of Human Resources Manager}

Filippetti (2015) noted that human resources manager plays an important role in hiring individuals for a company. He or she is responsible for hiring and training the new employees of a company. Other supervisors will frequently seek the input of an HR manager before they make the decision to hire an individual. In addition to managing the hiring of employees, HR managers also manage the payroll. They may also be responsible for organizing all of the contracts that a company has.

\section{HR Management Salary}

The Bureau of Labor Statistics reports that HR managers make about $\$ 99,000$ a year. This position is expected to grow only by 13 percent in the next ten years. One of the major reasons for the slow growth in demand is due to the fact that many companies are no longer hiring as many employees as they once did. There is no longer a need for multiple HR managers to work within a company. 


\section{Education Required}

According to Othman, \& Tek (2013) to become an HR manager you should pursue a bachelor's degree. The competition for HR positions can be fierce. An individual is no longer promoted to this position within a company due to his or her experience. Instead, an individual is usually promoted to this position when he or she has received a master's degree. One may have a degree in business management in order to take on a position as an HR manager. Some business schools also give individuals the opportunity to specialize in a human resources degree. He further posits that if an individual knows his dream career, then he/she should look at the programs that a college offers before he attends that college. You should try to take courses in employee contracts, accounting and business leadership.

\section{Skills}

Butler \& Lee (2013) suppose that to be an HR manager requires a lot of patience and diligence. There is a need to review the applications of people who are applying for positions as employees in a company. There is a need to do a thorough background check on each person who applies for a position in the company. It is up to the HR manager to discover whether a person has a criminal past. Ultimately, other supervisors will rely on your decisions and input in making their own choices regarding hiring or firing an employee. The HR Manager should also possess excellent written and oral communication skills and should enjoy being able to lead a team of employees.

\section{Responsibilities}

One of the major responsibilities that an HR manager has is in ensuring that applicants understand the terms of their employment agreements. He will need to work with the legal team of your company to ensure that he also understand employment agreements. The HR Manager may need to be able to explain the specific terms and conditions of a contract to all of the employees. He may also be given the responsibility of training any new employees that the company hires. The HR Manager should be able to help employees feel comfortable in the new positions that they are offered (Ding, \& Akhtar, 2015).

\section{Methodology}

Primary and secondary sources were obtained with the aid of a questionnaire. The use of the questionnaire was employed to gather relevant data from respondents. The secondary data was obtained from related journals and articles. The study examines the link between strategy human resources and Small-Medium Firm Performance of four indigenous reputable firms in the food and beverage industry which are: (i) Real confectionaries Nigeria Limited, Lagos Nigeria (ii) Agro Allied Food Enterprises Nigeria Limited, Lagos Nigeria (iii) Barracuda Food Limited Lagos Nigeria (iv) Adestar and Sons Nigeria Limited.

The study adopted a survey method. The entire population of the management staffs of the Four Firms in the food companies is 210 staffs. The questionnaire was administered to the population of the study but 184 questionnaires were duly returned. Data was analyzed using interferential and descriptive statistics. The inferential statistics involve regression, Analysis of Variance (ANOVA) and multiple regression analysis. A pilot study was also be used to test the quality, clarity, timescale and bias of the questionnaire as pointed out by Naoum (2002).

\section{Data Presentation and Analysis}

The demographic profile of Staff of a reputable organization in the food industry in terms of Educational qualification, Marital Status, Sex, Age and Working Experience are shown in Table 1 below.

Table 1. The demographic profile of Staff in terms of Educational qualification, Marital Status, Sex, Age and Working Experience

\begin{tabular}{|l|c|c|}
\hline \multicolumn{1}{|c|}{ Educational qualification } & Frequency & Percentage \\
\hline SSCE & 2 & 1.1 \\
\hline OND/NCE & 12 & 6.5 \\
\hline HND/BSc/MBA & 157 & 85.3 \\
\hline OTHERS Marital status & 13 & 7.1 \\
\hline Total & $\mathbf{1 8 4}$ & $\mathbf{1 0 0}$ \\
\hline & Frequency & 17.9 \\
\hline Single & 33 & 73.9 \\
\hline Married & 136 & 4.3 \\
\hline Divorce & 8 & 3.8 \\
\hline Widow & $\mathbf{7}$ & $\mathbf{1 0 0}$ \\
\hline Total & $\mathbf{1 8 4}$ & \\
\hline
\end{tabular}


Table 1 (cont.). The demographic profile of Staff in terms of Educational qualification, Marital Status, Sex, Age and Working Experience

\begin{tabular}{|l|c|c|}
\hline \multicolumn{1}{|c|}{ Sex } & Frequency & Percentage \\
\hline Male & 119 & 84.7 \\
\hline Female & 65 & 35.3 \\
\hline Total & $\mathbf{1 8 4}$ & $\mathbf{1 0 0}$ \\
\hline $20-30 \quad$ Frequency & 10.3 \\
\hline $31-40$ & 19 & 59.3 \\
\hline $41-50$ & 110 & 22.8 \\
\hline $50-$ above & 42 & 7.1 \\
\hline Total & 13 & $\mathbf{1 0 0}$ \\
\hline \multicolumn{1}{|c|}{ Working Experience } & $\mathbf{1 8 4}$ & Percentage \\
\hline $1-2$ years & Frequency & 2.7 \\
\hline $3-5$ years & 5 & 28.8 \\
\hline $6-10$ years & 53 & 44.6 \\
\hline $11-15$ years & 82 & 17.9 \\
\hline 16 years and above & 33 & 6.0 \\
\hline
\end{tabular}

Source: Researchers Field Survey 2016

Table 1 shows that the organization has S.S.C.E $1.1 \%$, OND/NCE 6.5\%, HND/BSc/MBA 85.3\% while others which constitute $\mathrm{PhD}$, M.Sc. and other advanced academic certificate has 7.1\%. These show that the staffs of the organization are educationally inclined to achieving performance in the organization. The marital status shows that single has $17.9 \%$, married $73.9 \%$, divorce $4.3 \%$ and widow $3.8 \%$. This shows that majority of the members of staff were married. This to some extent shows that the staffs are committed and responsible to their job. Considering the sex of members of staff in the organization, a male has $84.7 \%$ while a female has $35.3 \%$. This tends to follow the normal male/female staff distribution of many Nigerian organizations. Aside from this male are more active and agile than female in handling production and manufacturing in the food industry in Nigeria (Manufacturing Association of Nigeria (MAN), 2012).

In line with the working experience, $1-2$ yrs has 7\% 3-5 has 28.8\%, 6-10 yrs has 44.6\%,11-15 yrs has 17.9\% while 16 yrs and above has $6 \%$. This implies that the organization has men and women of vast experience that can help in achieving effective performance. More so the organization has men and women that can take robust decisions for better organizational performance.

\section{Test of Hypotheses}

\section{Hypothesis One}

Ho: There is no significant relationship between Strategic Human Resources Management practices and SmallMedium Firm Performance.

Table 2.1 Model Summary

\begin{tabular}{|c|c|c|c|c|}
\hline Model & R & R Square & Adjusted Square & Std. Error of Estimate \\
\hline 1 & $.715 \mathrm{a}$ & .511 & .501 & .500 \\
\hline
\end{tabular}

Source: Authors computation, 2016

a. Predictors (constant): SHRM practices

b. Dependent Variable: Small-Medium Firm Performance

$\mathrm{R}^{2}$ value of 0.511 reveals that Strategic Human Resources Management practices independently accounts for $51.1 \%$ of the variation of Small-Medium Firm Performance thereby accepting the alternative hypothesis and rejecting the null hypothesis.

Table 2.2 ANOVA

\begin{tabular}{|l|c|c|c|c|c|}
\hline \multicolumn{1}{|c|}{ Model } & Sum of Squares & Df & Mean square & F & Sig \\
\hline Regression & .134 & 2 & .134 & 45.072 & $.000 \mathrm{~b}$ \\
Residual & 16.304 & 182 & .230 & & \\
Total & 16.438 & 184 & & & \\
\hline
\end{tabular}

Source: Authors Computation, 2016

a. Predictors (constant): SHRM practices

b. Dependent Variable: Small-Medium Firm Performance 
The f-statistics of 45.072 shows that the model is statistically significant. It shows that there is a significant relationship between Strategic Human Resources Management practices and entrepreneurial performance.

\section{Hypothesis Two}

Ho: Size, maturity, planning level and availability of HR department do not significantly affect the SHRM practices of the organizations.

Table 3.1 Model Summary

\begin{tabular}{|c|c|c|c|c|}
\hline Model & R & R Square & Adjusted R Square & Std. Error of the Estimate \\
\hline 1 & $.811 \mathrm{a}$ & .658 & .642 & .401 \\
\hline
\end{tabular}

Source: Authors Computation, 2016

a. Predictors (constant): Size, maturity, planning level and availability of HR department

b. Dependent Variable: SHRM practices

$\mathrm{R}^{2}$ value of 0.658 reveals that Size, maturity, planning level and availability of HR department accounts for $65.8 \%$ of the variation in SHRM practices thereby accepting the alternative hypothesis and rejecting the null hypothesis.

Table 3.2 ANOVA

\begin{tabular}{|l|c|c|c|c|c|}
\hline \multicolumn{1}{|c|}{ Model } & Sum of squares & Df & Mean Square & F & Sig \\
\hline Regression & 1.289 & 2 & 1.289 & 19.127 & $.000 \mathrm{~b}$ \\
Residual & 10.026 & 182 & .141 & & \\
Total & 11.315 & 184 & & & \\
\hline
\end{tabular}

Source: Authors Computation, 2016

a. Predictors (constant): Size, maturity, planning level and availability of HR department

b. Dependent Variable: SHRM practices

The f-statistics of 19.127 shows that the model is statistically significant. It shows that Size, maturity, planning level and availability of HR department significantly affect SHRM practices of the organizations.

\section{Conclusion}

This study confirmed that a good HRM practice and entrepreneur training would be able to improve performance in small and medium enterprises. Although this study does not examine all dimensions of HRM, the results have provided clear evidence that there is a significant relationship between Strategic Human Resources Management practices and Small-Medium Firm. Although the SHRM practices involve high costs and risks, a firm has no choice, but to invest in this critical area of human and entrepreneurial capital so that their performance could be improved, which in turn would consolidate their competitive position in the marketplaces. From a theoretical point of view, investment in innovation alone is meaningless without a proper strategic HRM practice in organizations. This is especially true for Small-Medium Firms because unlike large firms that are able to engage a good number of high skill employees, the former with limited resources have limited access to such human assets. Therefore, training for entrepreneurs is also important for innovation to be carried out more effectively. Given the limitation of this study in terms of sample size, sub-industries and HRM dimensions, future studies should consider enlarging the sample size, by incorporating other subindustries and HRM dimensions such as planning, selection and recruitment, appraisal, labor relations, as well as health and safety of human resources. It was evident that HRM practices and entrepreneur training are critical for SMF performance.

\section{Recommendations}

From the findings of this study, the importance of HRM as a source of competitive advantage has long been identified. Therefore, the government has to provide training and human resource development through its industrial training institutes at all skill levels for job entry. The government should also make sure there is effectiveness and accountability in the Human Resource Development Fund (HRDF), based on a levy/grant system that provides training for participating employers. Training courses offered by government agencies are cheaper because they are substantially subsidized. Thus, the local SMFs have to find ways to manage human resources more efficiently and effectively in order to remain competitive in the globalized market. 
Employees are the organization's best assets and they should be a priority. There should be a performance evaluation system that will give organizations an opportunity to transform their employee's work experience into a motivating and content one allowing them to bring their best to work every day. HR Managers should do a comparative analysis after 6 months. Track the changes in the employees, their productivity and the overall performance of the organization.

There should be a link in the performance appraisal results with relevant training programmes. This will identify the gaps by analyzing the performance and provide appropriate inputs for the training. It is important to assess the results of the training programme at regular intervals to make it a success.

\section{References}

1. Becker, G. S. (1964). Human Capital: A Theoretical Analysis with Special Reference to Education. New York: Columbia University Press.

2. Bharadwai, S., \& Menon (2010). Making Innovation Happen in Organizations: Individual Creativity Mechanisms, Organizational Creativity Mechanism or Both? Journal of Production and Innovation Management, 17, 424-34.

3. Blackwell, Mark, S. K. M., \& Akhtar, S. (2013). Human Resource Management Practices, Strategic Orientations, and Company Performance: A Correlation Study of Publicly Listed Companies. Journal of American Academy of Business, 2(2), 510-515.

4. Butler, J. E., \& Lee, T. W. (2013). Regional Recovery and Development: The Role of HRM in East and Southeast Asia. Human Resource Management Review, 13, 367-372.

5. Carlson, D. S., Upton, N., \& Seaman, S. (2006). The Impact of Human Resource Practices and Compensation Design on Performance: An Analysis of Family-Owned SMEs. Journal of Small Business Management, 44(4), 531-543. Available at: http://dx.doi.org/10.1111/j.1540-627X.2006.00188.x.

6. Chew, Y. T. (2016). Achieving Organizational Prosperity through Employee Motivation and Retention: A Comparative Study of Strategic HRM Practices in Malaysian Institutions. Research and Practice in Human Resource Management, 12(2), 87-104.

7. Craig, A., \& Hart, S. (2005). Where to Now in New Product Development Research? European Journal of Marketing, 26(11), 1-49. Available at: http://dx.doi.org/10.1108/03090569210023037.

8. Cumming, B. S. (1998). Innovation Overview and Future Challenges. European Journal of Innovation Management, 1(1), 21-29.

9. Ding, D. Z., \& Akhtar, S. (2015). The Organizational Choice of Human Resource Management Practices: A Study of Chinese Enterprises in Three Cities in The PRC. International Journal of Human Resource Management, 12(6), 946-964.

10.Ferguson, K. L., \& Reio Jr., T. G. (2010). Human Resource Management Systems and Firm Performance. Journal of Management Development, 29(5), 471-494.

11.Ferguson, P. R. (2013). Industrial Economics: Issues and Perspectives. Hong Kong: Macmillan.

12.Filippetti, A. (2015). Innovation Modes and Design as a Source of Innovation: A Firm-Level Analysis. European Journal of Innovation Management, 14(1), 5-26.

13.Flynn, M., Doodley, L., \& Cormican, K. (2013). Idea Management for Organizational Innovation. International Journal of Innovation Management, 7(4). Retrieved 20 July 2011, from http://www.scribd.com/doc/10280292/IDEA-MANAGEMENT-FOR-ORGANISATIONALINNOVATION.

14.Goel (2013). Ownership Structure, Founder Leadership, and Performance in Norwegian SMEs: Implications for Financing Entrepreneurial Opportunities. Journal of Business Venturing, 18(5), 619-637.

15.Heneman, R. L., Tansky, J. W., \& Camp, S. M. (2010). Human Resource Management Practices in Small and Medium-Sized Enterprises: Unanswered Questions and Future Research. Entrepreneurship Theory and Practice, 25, 1-11. www.sciedu.ca/jms. Journal of Management and Strategy 4(2), 2013.

16.Hurley, R. E., \& Hult, G. T. M. (1998). Innovation, Market Orientation and Organizational Learning: An Integration and Empirical Examination. Journal of Marketing, 62, 42-54.

17.Jiménez-Jiménez, D., \& Sanz-Valle, R. (2005). Innovation and Human Resource Management Fit: An Empirical Study. International Journal of Manpower, 26(4), 364-381. Available at: http://dx.doi.org/10.1108/01437720510609555.

18.Johne, A. (2013). Successful Market Innovation. European Journal of Innovation Management, 2(1), 6-11.

19.Kellermanns, F. W., Eddleston, K.A., Sarathy, R., \& Murphy, F. (2010). Innovativeness in Family Firms: A Family Influence Perspective. Small Business Economics. 
20.Kramar, R.A., Noe, J., Hollenbeck, B. Gerhart, \& Wright, P. (2008). Human Resource Management in Australia: Strategy/People/Performance (3rd ed.). Sydney: McGraw-Hill Irwin.

21.Laursen, K., \& Foss, N. J. (2003). New Human Resource Management Practices, Complementarities and the Impact on Innovation Performance. Cambridge Journal of Economics, 27, 243-263. Available at: http://dx.doi.org/10.1093/cje/27.2.243.

22.Lin, C. H., Peng, C.H., \& Kao, D. (2008). The Innovativeness Effect of Market Orientation and Learning Orientation on Business Performance. International Journal of Manpower, 29(8), 752-772. Available at: http://dx.doi.org/10.1108/01437720810919332.

23.Love, L. G., Priem, R. L., \& Lumpkin, G. T. (2002). Explicitly Articulated Strategy and Firm Performance under Alternative Levels of Centralization. Journal of Management, 28(5), 611-627.

24.Otero-Neira, C., Lindman, M. T., \& Fernández, M. (2009). Innovation and Performance in SME Furniture Industries: An International Comparative Case Study. Marketing Intelligence and Planning, 27(2), 216-232.

25.Othman, R., \& The, C. (2013). On Developing the Informated Work Place: HRM Issues in Malaysia. Human Resource Management Review, 13, 393-406.

26.Petridou, E., Sarri, K., \& Kyrgidou, L. (2009). Entrepreneurship Education in Higher Educational Institutions: The Gender Dimension. Gender in Management: An International Journal, 6(4), 547-558.

27.Pfeffer, J. (1994). Competitive Advantage through People. Boston, MA: Harvard Business School.

28.Rae, D., \& Carswell, M. (2000). Towards A Conceptual Understanding of Entrepreneurial Learning. The Journal of Small Business and Enterprise Development, 8(2), 150-158.

29.Roberts, P. W., \& Amit, R. (2003). The Dynamics of Innovative Activity and Competitive Advantage: The Case of Australian Retail Banking, 1981 to 1995. Organization Science, 14(2), 107-122. Available at: http://dx.doi.org/10.1287/orsc.14.2.107.14990.

30.Rogers, M. (2010). The Role of Diversification on Firm Performance, Melbourne Institute Working Paper No. 00, ISSN 1328-4991, September.

31.Sekkel, \& Araújo, B. C. (2010). Economic Performance of Brazilian Manufacturing Firms: A Counterfactual Analysis of Innovation Impacts. Small Business Economics. 